\title{
sciendo

\section{Implementation of Blockchain Technology in Insurance Contracts Against Natural Hazards: A Methodological Multi-Disciplinary Approach}

\author{
Andrea Jonathan PAGANO ${ }^{1 *}$, Francesco ROMAGNOLI ${ }^{2}$, Emanuele VANNUCCI $^{3}$ \\ ${ }^{1,2}$ Institute of Energy Systems and Environment, Riga Technical University, Azenes iela 12/1, \\ Riga, LV-1048, Latvia
}

${ }^{3}$ Department of Business and Management, Pisa University, Cosimo Ridolfi street 10, Pisa, 56124, Italy

\begin{abstract}
Risk insurance for disasters plays a relevant part in the implementation of risk reduction strategies during the pre-disaster phase. This is essential to support risk management towards decreasing the marginal risk allowing policy holders to transfer risk to avoid considerable financial loads from the costs incurred during the recovery phase in a post-disaster phase. There is evidence that the introduction of an integrated risk insurance strategy for community resilience planning is still lacking. Thus, this undermines the possibility to have proper optimized holistic risk management; on the one hand this strengthens pre-disaster risk mitigation measures, mostly relying on mitigative infrastructural solutions, and on the other hand it better defines risk prevention strategies mostly connected to land planning and urban development. This paper will show how insurance markets can play a key role towards mitigating the economic consequences of natural and climate change disasters, and how essential it is to better quantify the beneficial effects and costs of engineer-based mitigative solutions. In this context, the legal framework into which the actuarial quantitative model can be implemented will support the creation of an integrated multidisciplinary approach with potential implementation on a novel platform capable of collecting and processing information from different sources and dimensions such as blockchain technology. The scientific community is, in fact, increasingly interested in implementing blockchain technology to overcome problems linked to the contractual dimension of natural disaster risk insurance which can be interpreted as a sort of smart contracting. Through a study that involved four distinct areas, namely: law, environmental engineering, insurance and IT, this paper proposes a specific multidisciplinary methodology to achieve the drafting and implementation of a digital insurance contract on a blockchain platform against natural hazards. This paper proposes the basis to advance a quantitative concept to optimize the impact of catastrophe risk insurance onto the community resilience; in fact providing a key synergy for definition of pre-disaster conditions.
\end{abstract}

Keywords - Blockchain; insurance; natural hazard; risk mitigation; risk reduction; smart contract

\section{INTRODUCTION}

Since the early 1970s, extreme events associated with natural disaster have been growing both in frequency and intensity. Specifically, during the last 15 years there is a recorded

\footnotetext{
* Corresponding author.

E-mail address: Andrea-Jonathan.Pagano@rtu.lv
}

(C2019 Andrea Jonathan Pagano, Francesco Romagnoli, Emanuele Vannucci.

This is an open access article licensed under the Creative Commons Attribution License (http://creativecommons.org/

licenses/by/4.0), in the manner agreed with Sciendo. 
increase of disasters at a rate of $2 \%$ [1]. This increase is reflected in economic losses [2], gaining the attention of the scientific and professional communities to find novel and effective methods of insurance as a resilient management tools for risk reduction.

According to the study of Paleari [2], there are several factors affecting the overall benefits and sustainability of insurance mechanisms when coping with natural disasters that are only in part directly insurance-related. The first one is related to the time reference. In fact, insurance works only in an ex-post situation in terms of compensation to minimize the effects of natural disasters. This perspective by Paleari [2] identifies an interesting dynamic affecting the demand for insurance coverage from citizens: the lower the insurance penetration is, the higher the pressure is on governments to finance disaster losses. In this context, if governments offer full compensation, there is less incentive for citizens to get insured, in turn decreasing the overall demand for insurance coverage.

The second one relies on the concept of disaster risk management [3] in connection with the prioritization of recovery [4] or risk reduction strategies [5]. In fact, prevention and mitigation are defined by insurance companies during risks and potential loss assessments creating a cap for the level of insurability (or re-insurability) faced with insurance accessibility and affordability [6]. Several studies highlight this very aspect also in terms of the moral hazard potentially undermining any economic benefit [7].

Moral hazards occur at the governmental level, where existing private insurance schemes reduce the priority to prevent risks at the individual level [2]. The drawback of moral hazard by insurance policyholders is reflected in mandatory schemes applying flat premiums [8]. Governments normally distribute uniform packages of catastrophe benefits generally as ex-post public compensation.

At the EU level, two main insurance schemes against natural hazards can be identified [2]. The first one is defined in terms of voluntary add-on insurance schemes where the coverage for natural hazards is optional and it is proposed by private insurers. This has the consequence of having low penetration and thus supporting ex-post Government assistance.

The second scheme applied is mainly based on the mandatory extension of property insurance to disaster risks. In this context, a model of using non-risk-based premiums is normally used in high-risk area risk-averse to guarantee affordability and availability. The second scheme type has the consequence to have higher insurance penetration, but with a bigger loss potential [6], [8].

Rumson [9] defines insurance as the proper mechanism to deal with the issue of information asymmetry among the insurer and the insured. In this dynamic, insurance can trigger a risktransfer between clients, the global insurance and capital markets [10], [11]. This could create a worldwide and interconnected risk transfer and (re)insurance markets from catastrophic losses occurring in a specific locality [11], [12] but shared globally.

By using this shared catastrophe information, in a non-speculative and competitive market, the price would be set upon the assessment of risk-reflective pricing [13]. For this reason, both sides within the stipulation of an insurance contract (i.e. underwriters and actuaries) need up-to-date access and availability of detailed and accurate information about the nature of the risks [14]. Bin et al. [15] identify how the price fixed by the insurance market represents a mechanism to raise awareness and potentially encourage risk-reluctant behaviour. If market alterations happen, these mechanisms can be weakened, resulting in negative societal effects [16].

Governments (and consequently legal entities) have a key connection to insurance. One example is flood insurance, which can be related to land planning, investments in adaptation, and coverage for some of the most vulnerable assets. [17] In this context and under the light 
of a growing increase of economic losses from disasters [18] in relation to weather/climate change (most evident for non-insured losses) [19], [20] more accurate risk evaluations need an enormous amount of data to be processed from different types of dimensions (e.g. environmental, geological, weather, insurance-specific, engineering, legal, socio-economic). Consequently, proper data platforms and the use of 'Big Data' need to be considered for pricing optimal insurance premiums [14]. In this way will be possible to lowering the risk of community prone to hazard in turn increasing the overall community resilience with a direct effect on the insurance premiums, in fact providing the possibility to allocate economic resources to more vulnerable locations. This aspect would be essential to create a solution to the problem on non-insured assets [13], and potentially result in an increased investment contributing to sustainable development in more resilient areas against weather/climate change-related disaster.

In this direction, informatics tools like "blockchain" are raising interest for applications in a wide range of fields including insurance. The key function of their use is to collect reliable information that can be used for a dynamic updating of contracts; this is one of the main opportunities presented by smart contracting, with an adequate support of legal context in which such contracts are merged, and one of the main issues to be developed for the full functioning of this kind of innovative business model.

The key point for the use of blockchain technologies for the insurance business is the feasibility of smart contracts in this sector and the answer seems to be positive for the so-called instantaneous insurance, i.e. contracts with short duration which imply an automatism in issuing and in paying the eventual benefit settled in the contract. One example of this is the flight delay insurance proposed by AXA, called Fizzy, completely developed on a blockchain platform.

The insurance sector, among many others, has an increasing interest for the application of blockchain technology, introduced by the milestone paper by the inventor Nakamoto [21], to its business, as shown by many documents of main insurance groups [22], [23] and consultancy firms [24]-[27] and we have arrived to the creation, in 2016, of the B3i, the first blockchain-centred insurance consortium [28].

One of the potential fields for application which still has to be investigated is peer-to-peer insurance or reinsurance [29], [30], though it must be said that, at present, they are no "real" peer-to-peer models, as they have a traditional insurance model or risk carrier behind them, supporting the heavy lifting of the insurance business. In this context, smart contracts representing an important innovation and a prototype solution based on the Ethereum blockchain have already been implemented [31]. It should be underlined, however, that the adoption of peer-to-peer insurance models by the wider public is not imminent since many customers still consider it necessary to interact with intermediaries [32].

This interconnection and multidisciplinary aspect can thus support the development of proper insurance-based mechanisms as an option of adaptation able to increase local resilience against different types of disasters. In this scope, blockchain technology represents a good platform to mitigate risk and vulnerability towards the collection and analysis of different data sources (i.e. Big data related to GIS systems, Environmental variables, Exposure data, Social media data, etc.) providing a real-time risk assessment, and thus a better definition of a risk-based pricing of insurance policies faced with potential losses.

This study would like to propose a novel approach as opportunity to decline risk-pricing of policies. These relate to a novel type of data collection technique and processing aiming to strengthening blockchain platform-based solutions merging information derived from 
inclusive and holistic data sources. In this way it would be possible to have predictions and pricing of risk on more extended and up-to-date empirical datasets.

This article also reveals how the adoption of blockchain technology involving a multidisciplinary framework can improve overall community resilience to natural disasters favouring adaptation strategies. The study proposes a consistent methodological approach identifying the role of insurance on risk adaptation, multi-dimensional data provision, and data processing for insurance price definition and the potential role played within a consistent legal framework.

Specific emphasis will be dedicated to highlight the capacity constraint that relates to the application of smart contracts to insurance against natural hazards. This paper will emphasize the potential use of blockchain technology for smart contracts which consider multi-periodic insurance coverage, exploiting the automatism allowed by blockchain technology for updating the contractual conditions, based on new and reliable information collected over time.

\section{METHOD}

When examining the issue on how to increase community resilience with novel insurancebased mechanisms, a systematic literature review was finalized. This part was mainly made on the analysis of scientific papers and grey literature.

In order to more consistently move towards the clarification of the research objectives, the research has been organized into these main steps:

- Role of insurance as adaptation measure to natural disaster;

- Smart contracts as insurance mechanisms against natural hazards;

- Blockchain overview;

- Blockchain and smart contracts: how they work.

The main results following the literature review will be implemented in a multidisciplinary manner that will serve as a framework to address the main challenges over the use of different data sources for the definition of a more updated and focused catastrophic (CAT) model for an optimized risk/premium evaluation.

Specifically, chapter 2 will better clarify the following main questions:

- What is a smart insurance contract?

- What are the experiences of implementing the blockchain technology in the insurance sector?

- What would be the difference of a standard smart insurance contract?

- Is there a regulatory framework capable of "accepting" smart multi-period insurance contracts? Possible multi-phase contracts with constant data flows. Analysis of the individual characteristics of the new contract;

- Is it possible to find any contractual declination to implement a multi-period smart contract?

- What structure could a smart multi-period contract have against natural hazard risk mitigation?

- What other aspects could it involve (e.g. Bayesian-quantitative and engineering profiles)? 


\subsection{Role of Insurance as Adaption Measure to Natural Disaster}

Insurance dynamics have a focal role in human progress and efforts to predict, mitigate, and adapt to natural disasters [19]. Effective insurance can be a tool to spread the communication of risk related to a certain geographical location. In order to perform successfully, premiums, coverage, and types of insurance must be risk-based and determined according to accurate information. Insurance dynamics against natural disasters have been evolving for several years [33] including theoretical and practical aspects from several fields of expertise. This multifaceted interaction is embracing classical risk assessment perspectives, environmental engineering and insurance dimensions, as well as from adaption and mitigation strategies in the administrative area of municipalities to contract determination.

In the global insurance dynamics context, the insurance instrument used most frequently today also uses a risk mitigation method related to natural disasters [34].

The mitigation methods can consist of different implementation declinations. For the purposes of this paper, clearly, the most interesting profile is related, on the one hand, to the supervision and the constant study of the area in which the immovable asset is placed, and on the other, to the creation of adaptation tools capable of decreasing the risk itself.

Specific examples of the use of insurance as dynamic mitigation tool to disaster are provided in the car insurance sector where the initial policy stipulated and the premium proposed within it can be dynamically be adjusted on the constant verification of the information implying a change of the asset de quo.

Risk mitigation, in compliance with this profile, consists in determining the topicality and the exposure of an asset according to the eventual occurrence of a hazard where the asset itself is placed [35].

In other cases, with a constant analysis and verification of an insured asset respect its initial status would be able to allocate part of the insurance premium to the implementation of mitigative measures due to a decreased risk affect the asset. In accordance with this second perspective, mitigation is effective, through the modification and improvement of the structure itself, is also expressly agreed [36].

\subsection{Smart Contracts as Insurance Mechanisms against Natural Hazards}

To highlight the scientific and practical gap of a specific smart contract insurance against a natural hazard, the first methodological approach, specifically legal, leads to a literature review of the state of the art of the thematic areas of implementation of smart contracts themselves.

"Smart contracts" are the development of the research carried out by Nick Szabo, who, in the 1990s was a reference author in the data encryption landscape. In 1997, he published two papers [37] in which he theorized a system of transfer of rights in the execution of a mathematical algorithm, inspired by the sales system of vending machines [38]. The following year he released the third paper in which he formalized the concepts outlined in previous works.

In his scheme, a specific property right is included in a title intended to circulate, together with related information.

The transfer is put into mathematical-cryptographic security and the ownership title is placed in a logical chain of previous similar securities as a guarantee of the continuity of operations [39]. 
The most important implementation of crypto-currency is the Bitcoin that is implemented in different protocol like Ethereum and its cryptocurrency Ether (second to bitcoin by capitalization and by currency/dollars exchange) [40].

This platform allows the use of the so-called smart contracts [41]. Thanks to the invention of the blockchain, in 2014 Vitalik Buterin outlined the characteristics of what then became the main platform for the development and performance of smart contracts: Ethereum. The purpose of this platform is to provide a blockchain - a tech-tool with built-in programming language, which can be used to build "contracts" and to encode functions, so that these contracts are self-executed in accordance with the pre-set rules: all this simply by writing the logic of their operation in a few lines of code [42].

There is no universally-accepted definition of smart contract, due to its recent appearance on the scene and its technological complexity. As described by Grasso et al. [43] the smart contract is defined as an agreement that is automatic updated finding the optimal condition among the parties involved in the insurance contract. This definition is showing the need to have a proper platform for providing the correct transactions which comply with the terms of the contract. Another definition was provided by the Italian IVASS (Italian Institute for Insurance Supervision) describing smart contracts as on-line modifiable contracts processed according to predefined contract rules, based on the creation of continuous updated depository of information of the insured assets [44].

In accordance with the fact that the characteristics of any good or data can be digitized and represented by a code, all this can be stored and secured in a distributed register, not only from a static but also a dynamic point of view; the operations and the agreements between the nodes of the network can be traced and their execution can be automatically performed by the blockchain itself without the intervention of intermediaries. All this has become possible thanks to smart contracts which, as IT protocols, formalize the elements of an agreement and automatically execute the terms of the agreement (terms that are therefore predefined) when the conditions foreseen by the agreement are fulfilled (even the conditions are therefore predefined and codified). In a nutshell, to provide an important statement in order to understand the operation of smart contracts "a smart contract is a piece of code which is stored on a blockchain, triggered by blockchain transactions, and which reads and writes data in that blockchain's database" [45].

The development and evolution of smart contracts has been sudden, their application is expanding day by day. In addition to Ethereum, other open source projects were born to create increasingly sophisticated smart contracts (like Counterparty and Mastercoin). To date, they have been used in the financial sector to automatically execute derivatives, futures, swaps and options. They have also been used to build platforms for the sale of goods on the internet, among unknown people, without the help of central authorities [46].

\subsection{Blockchain Overview}

The technology called "blockchain" is at the top of financial and political dynamics. It pertains to different areas, completely heterogeneous, often with reference to legal problems as well. However, there is no such thing as a globally recognized and summarized text that fully describes the potential and the areas of application that this technology can have. Literally the word "blockchain" means "concatenated blocks" and, even if there is no single one definition, it is possible to delineate it as a concatenation of blocks constituted by the set of verifiable transactions, with vertical or tree structure, able to connect different nodes, which are formed physically from the servers of each participant that are used by the subjects to take part and consciously adhere to the decision. The great versatility of the system 
is explained because there are different definitions and "blockchain"explanations that also depend on usage.

According to the first definition, a blockchain is a database of transactions: "The blockchain is a technology which allows the creation and management of a large distributed database for transaction management shareable between multiple nodes on a network" [47].

This definition therefore refers to a database structured in connected blocks, each of which contains multiple transactions, which are validated by the network itself in the analysis that is made of each block. Each node of the chain is physically constituted by the server through which each participant has access to the blockchain; sees, controls and approves all transactions.

For others, however, the blockchain best expresses the evolution of the concept of a "ledger" [48]. Before the advent of the blockchain, in relation to the systems that already allowed the exchange of transactions and information, the idea of centralized logic prevailed, in which everything was referred and managed by a single unit or authority, about which parties had confidence. With the concept of a decentralized ledger, it has become a phenomenon of decentralization of information: data is no longer guarded by a single central unit, but moves to external locations, which have become increasingly important in the transactions [49].

Internationally, the most important sector inherent in the implementation of this new technology is finance. More generally and always related to money transfer transactions, the blockchain has brought enormous new developments. In fact, blockchain technology makes it possible to provide a more direct flow of payment between the payer and the payee, even if the transaction lies beyond the borders of the same country, without the need for intermediaries and with advantageous costs and almost instantaneous speed. Today, there is a real financial revolution through the implementation of systems that are based on the blockchain and that will perhaps allow for solving issues such as fraud, threat detection or identity theft, ensuring a high level of safety [50].

\subsection{Blockchain and Smart Contracts: How they Work?}

In the insurance sector, forms of insurance have developed that use smart contracts. The first example is InsureETH, a UK startup, in the field of airline reimbursements and compensations. Another case is that of the pilot project of the American International Group (AIG) together with IBM and Chartered Bank, who worked together to develop multinational insurance coverage, preparing a blockchain insurance called smart contract. It is worth noting that recently AXA insurance [51], in order to deliver refunds following the delay or cancellation of flights, has developed an extremely interesting smart contract. The insurance called Fizzy, is revolutionary because, as described in the AXA portal, it excludes any kind of negligence, typical in traditional insurance dynamics. Smart insurance, regardless of any external event or subjective/objective liability, automatically compensates in case of flight delay [50]. This is happening thanks to the combination of parametric insurance and blockchain technology, which ensure the inviolability of data and contracts and can preview of the amount of compensation. An "ad hoc" protection that could not be simpler or more accessible: should the flight be more than two hours late; the customer is immediately and automatically compensated. AXA representative Jean-Baptiste Mounier, in talking about the essence of the smart contract, points out that "The smart contract is the party that decides whether or not we should indemnify the policy holder and triggers a payment request to our system. The use of a smart contract to trigger claims will add trust in the insurer/policy holder relationship" [51]. 
Therefore, the first two research questions concerning the implementation of smart contracts in the insurance sector offer room for some reflection. First, it is correct to highlight a propensity of the insurance world for technological experimentation, and, likewise, the contractual determination of AXA-Fizzy on the voluntary exclusion of any objective and subjective element in relation to the payment of compensation seems extremely interesting. Secondly, and this is the fundamental element, the key factor of the research, is that the implementation of blockchain technology in the insurance field is still firm and static to the consent mechanism element determined even if the future is uncertain. The gap therefore consists in the absence of a smart insurance contract capable and able to modify elements and parameters that are inherent to the accidents, to the probabilities, and therefore to the subjective element of the contract and its causa contrahendi, [52] at the same time without changing the consent of the parties.

To summarize the two research questions, it is possible to determine that smart contracts have had a rapid development and evolution, and that blockchain technology is being used and relegated to the automation of the mechanism of compensation in the insurance industry [53]. This huge implementation gap leads the way for the use of blockchain data storage technology and modification of the contractual structure. In practice, it is time to move from a purely refund insurance blockchain to a big data management one [54].

\subsubsection{The Difference Between a Standard Smart Insurance Contract and a Multi-Period Contract}

What would be the difference between a standard smart insurance contract, one with instant effect, compared to a multi-period contract? One of the main differences was highlighted at the end of the previous section. It is quite clear that the main difference is in the term "multi period". In this case it is appropriate to clarify this term, because multi-period is not necessarily synonymous with long-term just as the smart standard contract is not synonymous with short-term.

The desired multi-period implementation within smart insurance contracts is subject to the fact that, periodically, through the storage of data from external certified sources, using blockchain technology, the contractual structure can change, i.e. the premium, the sum of compensation, or the determination of the percentage of risk [55].

Therefore, even if facing with insurance to natural disasters, the determined periods may be related to prolonged periods. In this way, the determination of multi-mode concerns the scanning of temporal phases in which it is possible to change and modify essential elements of the contract without the latter termination or requiring a new agreement between the parties.

The second difference concerns the method of using blockchain technology. Picking up one of the smart contracts mentioned above in the insurance field, blockchain is simply used in two steps: i) validation of the insured event, such as the hours of flight delay, and ii) the payment of the sum of money.

In other words, in the very few applicative experiences that have taken place in the last few years, insurance companies first made use of blockchain technology as an instrument to verify an insured event. The information, using as an example the AXA contract, deriving from the airline are stored within the blockchain data flow and any event of delay beyond the allowed limit "unblocks" and acts as a check and authorization for the second step.

The one-dimensional perspective of the contract in relation to the uniqueness of the period, understood as a contractual phase, emerges clearly. The data entered and the "transformation" of this data through blockchain technology into legal effects, such as compensation, are 
contained in a single phase, without any possibility, that extends or changes the contractual structure. Therefore, in these one-dimensional insurance dynamics, blockchain technology performs as verifying agent, regardless of the will and the consensus of the parties or external events [56].

Nonetheless, the contract that, hopefully, will be implemented in the future, may involve a completely different dimension - that of periodic data scanning, aimed not at the termination of the contract, but at its evolution, change, and adaptation.

In the perspective of a multi-phase contract, using blockchain the relevant data, in accordance with the insurance dynamics against natural hazards, might able to create and store a network of useful information to counteract the harmful phenomenon of risk. The implementation, in addition to the aforementioned characteristics of a smart insurance standard contract, involves the perpetuation of the contract, step by step, following the flow of data and the physiological modification of the initial parameters to which the parties have expressed a consensus.

\subsubsection{Regulatory framework for Smart Multi-Period Insurance Contract and Possible Multi-Phase Contracts with Constant Data Flows}

The minimal and necessary features of a multi-phase contract are described as follows:

- Onerous, and therefore, taking up the standard scheme of an insurance contract, the agreement is based on the bilateral provision by which the insured party pays, at agreed intervals, a sum called the insurance premium, to the company, which, in the case that the insured event occurs, compensates the damaged party [53];

- Aleatory, in the sense that the insured event, even if determined, described, and outlined, is uncertain in its occurrence [5];

- information technology (IT), in the sense that the stipulation of the contract occurs through an online platform through blockchain technology. In particular, the methods of signature are constituted by the expression of consent through the use of a digital signature device;

- Blockchain Technology. A blockchain consisting of nodes and arcs can be fixed in the typical supply chain structure comprised of nodes and arcs and thus can be used to capture both organizational and network risks associated with the supply chain;

- Real time data flow, in the sense of an IT contract structure able to receive data and information related to the insured asset and related environment able to modify time after time the initial parameters set out in the stipulation of the contract [57];

- Automatic renegotiation, automatic consensus, in the sense that the contract, considering the flow of data, capable of physiologically modifying the initial parameters of the contract, is legitimated, in relation to the flow, to change economic conditions even when the new conditions result in peius for the so-called weak party, the insured subject.

An analysis of the contracts disseminated with the individual characteristics mentioned above can be carried out by determining some cases that are widespread within the Italian regulatory system.

As far as the cost of the contract is concerned, this is meant as the one in which a subject receives an advantage in exchange for a non-gratuitous disbursement, defined as performance. There is a close relationship between advantage and performance, a causal link. A typical example in the Italian civil code is represented by the sale, regardless of whether it concerns movable or immovable assets, in which a subject pays a sum to another party and the latter, as a counter-claim, sells the asset de quo [56]. 
The dynamics inherent in the concept of "aleatory", on the other hand, pertain to the uncertainty of the occurrence of a determined event. Remaining in the specific theme of research and paper, clearly the insurance contract is a perfect example [58].

IT technology is inherent in the inevitable chaos of digital contracts. In particular, a digital contract is an agreement entered into on an online platform through which legal effects desired by both parties emerge. One of the best-known digital contracts is certainly the one related to e-commerce platforms, through which the buyer, in exchange for a payment, in most cases by credit card or similar means, purchases one or more assets on a website, which can act as a vendor tout court (Nike store, Ticketone) or as a mere intermediary (Amazon, Ebay). More generally, IT technology makes it possible to exchange not only information on the internet, but, for the first time, properties as well. Not therefore the simple payment or exchange of goods and services, but, thanks to this innovation, any other form of collaboration between people can take advantage of the possibilities offered by the network. All transactions carried out to date and verified directly by the system are recorded in it. In fact, transactions are only possible if they are approved by $50 \%+1$ of the nodes [59].

The European association of credit institutions has, in one of its reports, expressed a positive opinion about the reliability of the blockchain system. The main characteristic of the whole architecture of computer science can be synthesized with a single term: decentralization. In fact, there is no central repository in any blockchain but a peer-to-peer between users, by entering transactions in blocks [60]. In standard blockchain architecture, transactions are created from active components inserted in the network: the active user is called "node" and transfers Bitcoin to another node inserted in the network. The blocks of the network are created, in a chain, by other participants in the architecture that are defined as miners. To create blocks, miners must solve complex algorithms and, if they succeed, they are rewarded with bitcoins. The newly created transaction is distributed and validated following a rigid verification protocol to avoid, among other issues, the problem of "double spending". In practice, the validity of one transaction is confirmed with the consent of the nodes of the network on the basis of parameters set for the operation of the network itself. The nodes that validate a transaction are rewarded with Bitcoins. When the validity of the transaction is verified, the miners put it in a block and the transaction is executed (performed) with full respect to privacy [42].

The data flow, as consecution of information entered in an IT platform, can be understood thinking of what is set out above regarding the smart insurance contract on air delay. The peculiarity of this contract is the discrepancy between the initial condition, and, therefore, the uncertainty inherent in the event, and the event itself. In practice, following the random logic of the insurance contract, the peculiarity consists in the input of data in real time and the consequent immediate simultaneous supply of the sum established in favor of the insured subject. The modification of the facts as well as the occurrence of any event, are elements able to produce legal effects directly embedded within the blockchain technology [43].

In the determination of a new possible contract, the flow of data excluding the provision of any sum, it would have exactly the same function previously proposed.

The last single feature inherent to the possible implementation of the contract de quo, concerns the forecast and contextual acceptance of the parties, of the modification in fieri of the economic conditions.

This profile is closely linked to the data flow above. In particular, a data entry could be envisaged as per the insured asset, as well as the surrounding environment, capable of modifying the economic conditions, and therefore the insurance premium [61]. 
A contract to refer to and to use as a potential analogous tool is the so-called "variable interest rate mortgage".

A variable rate mortgage is a type of mortgage where interest rates vary based on the performance of certain parameters indicated in the contract.

The reference parameters to which the interest rates are linked are usually the Euribor (EURo Inter Bank Offered Rate, i.e. the average interest rate of the financial transactions in Euros between the main European banks), the IRS (Interest Rate Swap) - EuroIRS or the Official ECB Reference Rate. The Euribor (Euro Interbank Offered Rate) is the interest rate used as an indexing parameter for variable-rate mortgage loans. The Euribor has replaced the national indexes since January 1, 1999.

Euribor is calculated daily as a simple average of the quotations recorded by a group of banks representing the European and world credit panorama selected by the European Banking Federation.

The reference rate for variable-rate mortgages is published daily at 11 a.m. (GMT) by a group of banks representing the European credit landscape. There are currently 20 institutions that contribute to the Euribor [62].

Summarizing the main section, regardless of the will of the parties that have signed the contract, the data coming from a third party, the may involve economic changes Should the Euribor, with the flow of data, be capable of modifying, inaudita altera parte, with the increase or decrease of the interest rate, the economic conditions, may impose changes on the parties. A similar idea can be applied to insurance smart contracts against natural hazards. The flow of data entered into the digital blockchain platform is capable of modifying the parameters, such as risk and insurance premium, regardless of the parties' will [63].

\subsubsection{Implementation of the Multi-Period Smart Contract: Potential Drawbacks for the Smart Insurance Contract against Natural Hazards}

In this first methodological phase, the authors, by background and by connection with local insurance companies, have focused attention on the study of the normative dimension within the Italian panorama.

It is necessary to define the standard insurance contract within the Italian civil code which, moreover, in substance, does not differ absolutely from that of other major European countries. Article 1882 of the civil code states that insurance is the contract with which the insurer, following the payment of a fee, defined as a premium, is obliged to compensate the insured, within the agreed limits, for the damage that the latter suffered from a claim, or to pay a sum or an annuity upon the occurrence of an event related to human life.

Therefore, the first characteristic outlined, namely the fact that the contract is onerous, is absolutely transferable to the new agreement as an essential element and inherent to the definition.

Regarding the alea, as a determining element of the insurance contract, the risk is attributable to the abstract possibility that a damaging and detrimental event of a certain interest of the subject occurs. It is easy to understand how it can remain in a "latent" shape, more properly potential or materialize, when that possibility mentioned in abstract terms becomes real. The risk must therefore be possible (albeit with a greater or lesser likelihood of verification that affects only the amount of the premium), but objectively uncertain (i.e. caused by external causal factors and not by the parties, unaware of the possibility of occurrence and when), while, as mentioned, harmful and detrimental to the protected interest. The state of objective and absolute uncertainty that characterizes its essential features with the probabilistic forecast of the fact, human or natural, which is detrimental to the protected 
interest must already exist effectively at the time of adherence to the policy, since its lack $a b$ origine determines the invalidity ex tunc of the contract due to absence of cause (art. 1895), while the termination of the contract results in the termination of the relationship, again for lack of a causal justification. And, therefore, even this single characteristic has no impediment to its inclusion in the new contract.

The next three characteristics, i.e. IT, blockchain and real-time data flow, can be analysed together. In particular, since these characteristics are extremely distant from the determinations referred to in the 1942 civil code, it is possible to make a comparison in relation to the contractual experiences that have developed in recent years. As mentioned above, it is precisely the AXA contract, to give an example, among the particular implementations of blockchain technology in the insurance sector that provides a methodological answer. In fact, the AXA contract perfectly encompasses the three characteristics de quibus.

Without going into detail already explained in the previous section, the smart insurance contract against flight delay, integrates IT consistency, being completely digital, able to be stipulated by using an app on a smartphone.

It also uses blockchain technology, and by reconnecting to the third profile, it uses the aforementioned technology to: 1) verify the flow of data, in particular the possible communication of the delay or arrival on flight time, 2) certify the information received, and 3) pay the agreed sum in the case of delay.

For the purposes of drafting this paper, it is worth highlighting that almost all the features, some of which are inherent $e x s e$, such as compensation and the alea, others for subsequent implementation, such as IT, the flow of data and blockchain, are adaptable to our contract implementation project.

In regards to the dynamics of the renewal of the consensus to change the initial parameters of a contract, it seems appropriate to briefly outline a double scenario. Prima facie, the dynamics of the variable rate inherent to the loans, by structure and contractual frame work do not seem to coincide with the insurance dynamics, and therefore, and this is the trait d'union with the section of engineering mitigation risk, [64] it appears extremely prudent to operate a contract in which a high premium insurance is envisaged, above the real initial risk. In particular, when the initial conditions change in peius, the premium in any case continues to be suitable from the point of view of the insurance company for the continuation of the activity, and when, with determined time scans, reconnecting to the theme of the multi-period, the risk conditions reduce the difference between the bonus paid and the premium that, ideally, would be corrected from a mathematical point of view, could be used to create risk mitigation structures. [65]

With regard to possible implementation and the combination of purely legal aspect, i.e. civil insurance and smart contract latu sensu, it is worthwhile to add that Italy has proved to be a precursor of the times and has promulgated a specific regulation, D.L. 135/2018 modified in L. 12/2019, currently in the implementation definition phase.

As far as European regulations are concerned, the supranational legislator, within the smart contract discipline, including cryptocurrencies and blockchains, has moved along two lines. On one hand, through the introduction of binding regulations, such as, Regulation 910/2014 (which repeals Directive 1999/93/EC) 1127/201; and on the other, through mere resolutions, notably 2018/2185 of 13.12. 2018, addressed to specific bodies within the Parliament, urging the Commission to develop a draft of technical standards at the level of the relevant international organizations, such as ISO, ITU and CEN-CELENEC and to promote an analysis of the existing regulatory framework in the various Member States in order to verify the 
overlap and applicability of smart contracts, strengthening, if possible, their validity through legal coordination or mutual recognition among Member States.

\subsubsection{Other Aspects in Insurance Smart Contract: Link with a Bayesian-Quantitative and Engineering Context}

The closure of the aforementioned section and the simultaneous and relative apparent impossibility of operating an analogue implementation between insurance and loans, determines a mandatory and natural involvement of two distinct scientific areas. The first is actuarial science, the application of which, prodromal to the implementation of the contract, consists of the draft of a Bayesian model and engineering science to determine possible risk mitigation structures in relation to the income of difference between insurance premium and the actual risk borne [66].

Considering the current instruments for an economic mitigation of cat-risks due to natural hazards, traditional reinsurance, cat-bonds and resilience bonds, our Bayesian approach concerns a similar approach to the resilience bonds scheme that is not only compensation coverage of eventual damages, but also the chance of financing infrastructures for mitigating risks. Our methodological proposal is based on the calculation of an insurance premium at issue date and at every updating time, based on information collected at each time in a classic Bayesian adaptive scheme, such that the premium level may automatically change over time. Furthermore, at each renewal scan time, part of the eventual surplus of the premium paid in respect to the payments procured for damages shall be (automatically, settled in contractual conditions) used for financing mitigative infrastructure. Blockchain technology has the role of certifying reliable new information and also the state of mitigative infrastructure, which can vary according to the use of the surplus as mentioned before [67].

\section{RESUlTS AND DISCUSSION}

From the proposed literature review, it is highlighted that a blockchain technology applied to smart contracts in the insurance sector against natural hazards has an important role and, as of yet, unexplored potential.

In fact, the blockchain and smart contracts could have a tremendous impact on the use insurance in disaster risk reduction (DRR) strategies, in turn strengthening resilience to natural disasters. In this way, the implementation of a blockchain platform would speed up claims processing, reduce operating costs, and have the possibility to develop a more up-to-date policy premium in real time. In this scenario, a smart contract could facilitate reimbursements based on data collected from various available sources including a connection with cloud-stored 'Big-data'.

With this in mind, this paper proposes a methodological approach using the blockchain as supporting platform technology involving four distinct scientific areas which are interconnected inextricably: engineering, insurance-actuarial, legal, and IT (Fig. 1).

This represents an innovative multidisciplinary platform towards an optimized interaction of the regulatory, insurance, and engineering dimensions in order to move towards the development of a tool capable of implementing the potential data processing of different types of information: the use of the blockchain technology within risk reduction strategy to natural hazards can support this transition. 


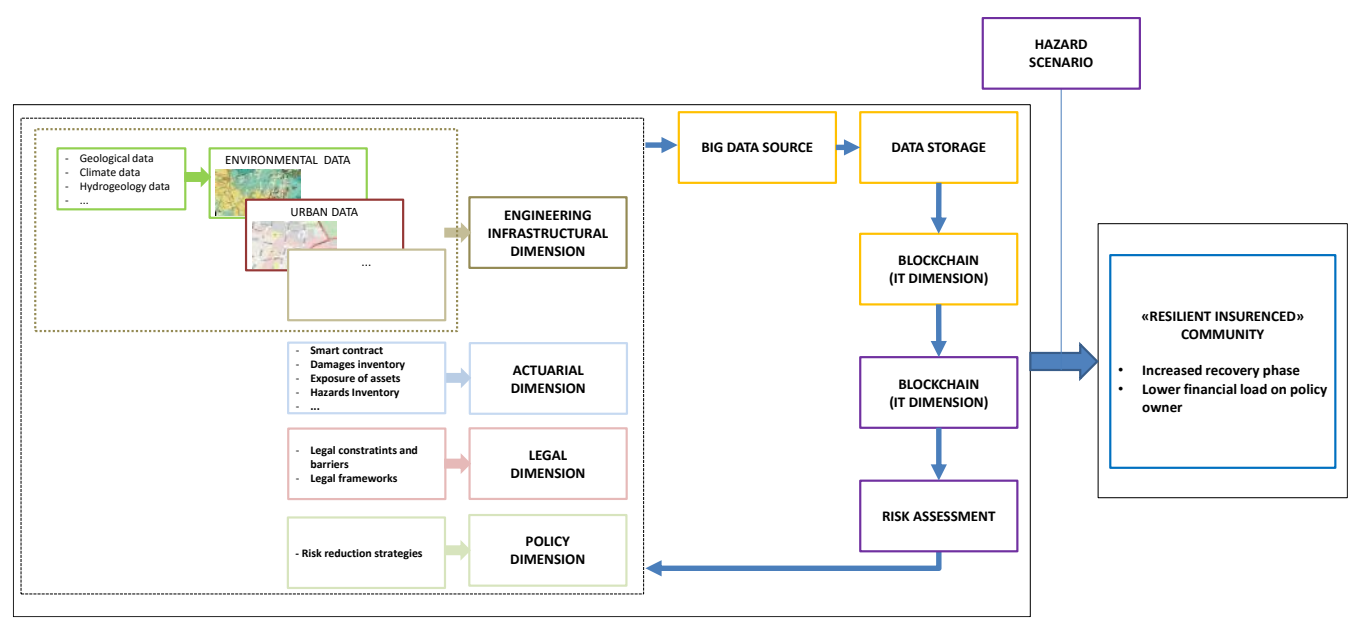

Fig. 1. Novel multi-disciplinary approach for blockchain implementation.

In this specific definition, a blockchain platform customized for the insurance market on "community" risks could be applied for an environmental risk in a certain geographical area, the potential damages of which are borne by both individual citizens and the public administration of the entire community.

Disciplines involved:

- Engineering: estimate of the probability of an accident due to environmental risk (i.e. floods), design and evaluation of risk mitigation tools, estimate of potential damage;

- Legal: legislation for the possibility of public-private synergies, both for investments in risk mitigation tools, and for implementing "community" forms of insurance, and for supervising the digital platform;

- Actuarial: quantification of the bonus for the transfer of the coverage of the potential damage (also in terms of reinsurance layers);

- IT: setting up a digital platform (blockchain) in which the subjects that take charge of the risk (public administration, private, insurance already in place), offer parts of the risk coverage to potential investors, with "prices" (premiums) already agreed according to actuarial valuation principles.

Merging the information coming from different data sources and disciplines in the proposed methodological approach, the role of blockchain technology is the certification of the collected information and the automation with which the contractual terms (i.e. the premium level and the sharing of the surplus) should change at each updating time. Such automation is the core of the concept of smart contracting, that is an update of the contract without a new bargain between the two parties. The legal aspects such that smart contracting is really admissible for this kind of insurance contract, have been analysed in the paragraph above.

The first step of the proposed methodological approach will be oriented towards the creation of an inventory of local hazards, the assessment of their occurrence, and the overall potential impact on the asset at risk based on patrimonial and non-material damages [68]. Finally, the definition of potential specific mitigation strategies applicable in a local context should be mapped and included within an overall inventory. Through this process, the assessment of the potential benefits of mitigation strategies addressed within the infrastructural dimension should be carefully explored. 
The proposed innovative platform based on the developed approach could give an opportunity to use open source data and "Big data" in a certified and validated way. In the context of defining the premium via a computation/risk assessment, the blockchain would play the role of a shared ledger recording a history of persons (both physical \& legal in terms of previous claims, committed infractions, health history, damages, etc.) and immovable assets. Insurance companies could trust the data use for the policy definition and automatically (and up-to-date) determine the premium. In this perspective, blockchain and smart contracts could be used in a flexible way even activating or deactivating certain policies and coverage, based on data collected and validated by the platform itself.

Within this view, blockchain technology represents a good platform to mitigate risk [69] and vulnerability towards the collection and analysis of different data sources [70] (i.e. Big data related to GIS systems, Environmental variables, Exposure data, Social media data, legal constraints, etc.). In this way, a real time risk assessment and thus a better definition of a riskbased pricing of insurance policies faced with potential disaster losses will be possible.

This would thus represent a more advanced system to use insurance as a more adaptive risk reduction tool aiming to increase the overall resilience and to better allocate financial resources towards more vulnerable areas.

The application of such an approach could also play a relevant role for urban disasters for which disaster management is still an issue that needs innovative approaches to build urban resilience strategies. Moreover, this perspective becomes even more relevant towards sustainable development plans and strategies according to the framework of the so-called Sustainable Energy and Climate Action Plans (SECAPs) for Municipalities [71].

Nevertheless, there are several concerns about the adaptation of a blockchain-based platform for smart contracts even including those for natural disasters. As mentioned by Gatteschi et al. [72], one limitation is scalability. This implementation limit is related to the fact that, although the transactions in a given system are relatively low, the possibility of flow congestion of the connected servers is high, and in a contractual context, this aspect certainly represents a limitation. This also increases the risk that accidents could occur during the transaction. Furthermore, the same study highlights that there is a criticality on the integration of different application developed by different blockchain platforms. Finally, there is an intrinsic complexity of the platform itself when experienced by "average users". This could lead to scepticism of fraud associated with blockchain products like Bitcoin.

After having explained the section dedicated to the actuarial part [73], it is necessary to explain the multidisciplinary connection. In fact, the latter is fundamental for innovative technological implementations [74] and shall pay attention to a new possible contractual implementation in the insurance field [75].

Specifically, the proposed approach proposed is a Bayesian calculation method.

Regarding the last methodological part - IT - the authors, stating that for logical consequence they preferred to focus on the areas mentioned above, the IT sphere has been addressed through a specific method on the study of the various blockchain platforms and on the empirical evidence of a stipulation of a smart contract.

\section{Conclusions}

Insurance dynamics against natural disasters have been evolving for several years. The theoretical and practical aspects involve several fields of expertise in a multifaceted interaction among environmental, engineering and insurance dimensions. 
This paper proposes a basis for a quantitative framework to strengthen the role of risk insurance for risk reduction strategies towards a potential blockchain platform merging actuarial, legal, and engineering dimensions.

The novelty of this paper is two-fold: first, the paper identifies the potential of using already existing mechanisms, like the periodic premium renewal in smart contracts, applicable to natural disaster insurance; second, the paper highlights the need for a more quantitative approach including a multi- and inter-disciplinary framework interfacing on a blockchain platform.

Within this paper, the possible benefits of the implementation of blockchain technology from an insurance perspective in terms of assets at risk, has been proposed.

The methodological perspective that the authors have chosen is relevant for reducing risk from several perspectives. In particular, in the first place, it allows an analytical study of the immovable asset insured and, for this reason, the above determinations involve a greater knowledge of the area involved and a lower risk of an unexpected disaster. As explained below, the final insurance agreement allows an investment of a variable amount to be allocated exclusively toward risk mitigation.

The authors point out a first result, in the sense of highlighting an evident regulatory gap within the insurance scenario, also outlining the numerous advantages that would derive from the implementation of blockchain technology under a Bayesian quantitative method.

Moreover, it is worth highlighting that in Italy and, more broadly, in Europe there is regulatory framework capable of welcoming the proposed smart contract, and the clear proof is the example set out in the Fizzy Axa contract. There are no impediments to the implementation of the insurance contractual framework through blockchain technology, with real-time data flow.

The aforementioned flow, due to the substantial and regulatory differences highlighted between the insurance contract and the variable rate mortgage is an example of a contract capable of changing economic conditions to outline the time and the risk and the relative "correct" insurance premium.

It is precisely from the apparent impossibility mentioned above that the engineering risk mitigation profile originates. If it does not seem possible to change the economic conditions for the weak party in peius, there are no impediments for both parties to decide for an insurance premium higher than the initial risk. This can be based on the establishment, at each scan time period, the any surplus between actual damage coverage and paid premium insurance is intended for the implementation and construction of risk mitigation measures.

The output of this scientific paper can be divided into three sections: the first concerns the creation of a methodological basis through which to outline all or part of the implementation research project as set out above. Therefore, the first output concerns the explanation of "how" possibly reaching a normative, engineering and actuarial implementation and improvement. Secondly, the paper seeks to highlight the regulatory provisions, especially in Italy, within which insurance companies can move in the field of smart contracts, in particular by connecting these to a dimension against natural hazards.

The main outcomes of the present study are thus oriented towards the proposal of a novel multidisciplinary approach considering legislative, engineering and actuarial dimensions. The aim is to create an assessment tool for the insurance sector in order to quantify the benefit of mitigative risk reduction measures coping against natural hazards. 


\section{ACKNOWLEDGEMENT}

This research is funded by Erasmus+, project "CABARET: CApacity Building in Asia for Resilience EducaTion".

\section{REFERENCES}

[1] Serre D., Heinzlef C. Assessing and mapping urban resilience to floods with respect to cascading effects through critical infrastructure networks. International Journal of Disaster Risk Reduction 2018:30(B):235-243. doi:10.1016/j.ijdrr.2018.02.018

[2] Paleari S. Disaster risk insurance: A comparison of national schemes in the EU-28. International Journal of Disaster Risk Reduction 2019:35:101059. doi:10.1016/j.ijdrr.2018.12.021

[3] UN General Assembly. Resolution 69/283 of 23 June 2015. Sendai framework for disaster risk reduction 2015-2030.

[4] Flood Hazards in Central Europe. USA: World Bank, 2012.

[5] Porrini D., Schwarze R. Insurance models and European climate change policies: an assessment. European Journal of Law and Economics 2014:38(1):7-28. doi:10.1007/s10657-012-9376-6

[6] Freeman P. K., Scott K. Comparative analysis of large-scale catastrophe compensation schemes. Catastrophic Risks and Insurance - Policy Issues in Insurance. Paris: OECD, 2005:187-234.

[7] Quesne F., Tollman J. Risk transfer and insurance for disaster risk management: evidence and lessons learned. Proceedings of the 5th Global Platform for Disaster Risk Reduction. Germany: GIZ, 2017.

[8] OECD. Financial Management of Flood Risk. Paris: OECD, 2016.

[9] Rumson A., Hallet S. Innovations in the use of data facilitating insurance as a resilience mechanism for coastal flood risk. Science of the Total Environment 2019:661:597-612. doi:10.1016/j.scitotenv.2019.01.114

[10] Cervantes-Godoy S., Kimura D., Antón J. Smallholder Risk Management in Developing Countries. OECD Food, Agriculture and Fisheries Papers 2013:61.

[11] Dahlen S., Peter G. Natural Catastrophes and Global Reinsurance - Exploring the Linkages. BIS Quarterly Review 2012.

[12] Abdullayev K. Global Reinsurance Market, 2013.

[13] Kunreuther H., et al. Insurance, Economic Incentives and Other Policy Tools for Strengthening Critical Infrastructure Resilience: 20 Proposals for Action. USA: Wharton University of Pennsylvania, 2016.

[14] Actuaries Institute. The Impact of Big Data on the Future of Insurance. Green Paper. Sydney: Actuaries Institute, 2016.

[15] Bin O., et al. Flood Hazards, Insurance Rates, and Amenities: Evidence from the Coastal Housing Market. Journal of Risk and Insurance 2008:75(1):63-82. doi:10.1111/j.1539-6975.2007.00248.x

[16] Hudson P., et al. Incentivising flood risk adaptation through risk based insurance premiums: Trade-offs between affordability and risk reduction. Ecological Economics 2016:125:1-13. doi:10.1016/j.ecolecon.2016.01.015

[17] Surminski S., Oramas-Dorta D. Flood insurance schemes and climate adaptation in developing countries. International Journal of Disaster Risk Reduction 2014:7:154-164. doi:10.1016/j.ijdrr.2013.10.005

[18] Choi T.-M., Lambert J. Advances in Risk Analysis with Big Data. Risk Analysis 2017:37(8):1435-1442. doi:10.1111/risa.12859

[19] Rumson A., Stephen H. Opening up the coast. Ocean and Coastal Management 2018:160:133-145. doi:10.1016/j.ocecoaman.2018.04.015

[20] Stoeckli E., Dremel C., Uebernickel F. Exploring characteristics and transformational capabilities of InsurTech innovations to understand insurance value creation in a digital world. Electronic Markets 2018:28(3):287-305. doi:10.1007/s12525-018-0304-7

[21] Nakamoto S. Bitcoin: A Peer-to-Peer Electronic Cash System; 2008 [Online]. [Accessed 19.02.2018]. Available: https://bitcoin.org/bitcoin.pdf

[22] Higgins S. Insurance Giant Allianz France Exploring Blockchain Potential [Online]. [Accessed 30.06.2016]. Available: http://www.coindesk.com/allianz-france-exploring-use-cases-with-blockchain-startup/

[23] Insurance Times Newsdesk. AXA leads 55m investment in blockchain [Online]. [Accessed 29.06.2016]. Available: http://www.insurancetimes.co.uk/axa-leads-55m-investment-in-blockchain/1417270.article

[24] Ramada M. For insurers blockchain is the new black [Online]. [Accessed 29.12.2017]. Available: http://blog.willis.com/2016/12/for- insurers-blockchain-is-the-new-black

[25] Shelkovnikov A. Blockchain Applications in Insurance. London: Deloitte LLP, 2016.

[26] Lorenz J.-T., et al. Blockchain in Insurance-Opportunity or Threat? USA: McKinsey Company, $2016: 19$.

[27] McKinsey Company. Blockchain Technology in the Insurance Sector. Proceedings of the Quarterly Meeting of the Federal Advisory Committee on Insurance (FACI). USA: McKinsey Company, 2017.

[28] Higgins S. European Insurance Firms Launch New Blockchain Consortium [Online]. [Accessed 29.12.2017]. Available: http://www.coindesk.com/europe-insurance-blockchain-consortium

[29] de Broglie L., et al. insPeer [Online]. [Accessed 29.12.2017]. Available: http://www.inspeer.me/ 
[30] Kunde T., et al. Friendsurance: The P2P Insurance Concept [Online]. [Accessed 29.12.2017]. Available: http://www.friendsurance.com/

[31] Davis J. Peer to Peer Insurance on an Ethereum Blockchain [Online]. [Accessed 29.12.2017]. Available: http://www.dynamisapp.com/whitepaper.pdf

[32] Young E. Voice of the Customer. Time for Insurers to Rethink Their Relationships. London: EY, 2012.

[33] Sawada Y., Takasaki Y. Natural Disaster, Poverty, and Development: An Introduction. World Development 2017:94:2-15. doi:10.1016/j.worlddev.2016.12.035

[34] Botzen W. J. W., van den Bergh J. C. J. M., Bouwer L. M. Climate change and increased risk for the insurance sector: a global perspective and an assessment for the Netherlands. Natural Hazards 2010:52(3):577-598. doi:10.1007/s11069-009-9404-1

[35] Lu Y. The blockchain: State-of-the-art and research challenges. Journal of Industrial Information Integration 2019:15:80-90. doi:10.1016/j.jii.2019.04.002

[36] de Ruig L. T., et al. A micro-scale cost-benefit analysis of building-level flood risk adaptation measures in Los Angeles. Water Resources and Economics 2019:100147. doi:10.1016/j.wre.2019.100147

[37] Szabo N. The Idea of Smart Contracts, 1997. [Online]. [Accessed 18.11.2018]. Available: http://szabo.best.vwh.net/idea.html

[38] Szabo N. Read related articles on Internet economics and Security. Peer-Reviewed Journal of the Internet 1997:2(9):1-24.

[39] Perugini M. L., Checco P. D. Introduzione agli Smart Contracts. SSRN Electronic Journal 2015. doi: $10.2139 / \mathrm{ssrn} .2729545$

[40] Ecosystem of existing crypto-currencies. Available: http://coinmarketcap.com

[41] Khan M. A., Salah K. IoT security: Review, blockchain solutions, and open challenges. Future Generation Computer Systems 2018:82:395-411. doi:10.1016/j.future.2017.11.022

[42] Buterin V. A Next-Generation Smart Contract and Decentralized Application Platform. Ethereum White Paper, 2014.

[43] Grasso A. Smart Contracts: Adoption Value for Enterprises and General Use Case, 2018.

[44] Istituto per la Vigilanza sulle Assicurazioni. Relazione sull'attività svolta dall'Istituto nell'anno 2016. (Report on the activity carried out by the Institute in 2016.) Istituto per la Vigilanza sulle Assicurazioni, 2016.

[45] Greenspan G. Beware of the Impossible Smart Contract [Online]. [Accessed 12.04.2016]. Available: http://www.theblockchain.com/2016/04/12/beware-of the-impossible-smart-contract

[46] Wright A., de Filippi P. Decentralized Blockchain technology and the rise of Lex Cryptographia. SSRN Electronic Journal 2015. doi:10.2139/ssrn.2580664

[47] Bellini M. Cos'è̀, come funziona e gli ambiti applicativi in Italia. (What it is, how it works and the application fields in Italy.) [Online]. [Accessed 26.09.2019]. Available: https://www.blockchain4innovation.it/esperti/blockchainperche-e-cosi-importante (in Italian)

[48] Vranken H. Sustainability of bitcoin and blockchains. Current Opinion in Environmental Sustainability 2017:28:1-9. doi:10.1016/j.cosust.2017.04.011

[49] Boucher P., Nascimiento S., Kritikos M. Come la tecnologia blockchain può cambiarci la vita. (How blockchain technology can change our life.) Brussels: Parlamento Europeo, 2017. doi:10.2861/13366

[50] García-Valls M., Dubey A., Botti V. Introducing the new paradigm of Social Dispersed Computing: Applications, Technologies and Challenges. Journal of Systems Architecture 2018:91:83-102. doi:10.1016/j.sysarc.2018.05.007

[51] AXA - Comunicato Stampa. AXA fa decollare in Italia Fizzy, la prima assicurazione viaggio al mondo basata su tecnologia blockchain che rivoluziona l'esperienza cliente. [Online] [Accessed 11.06.2018] Available: https://corporate.axa.it/-/axa-italia-premiata-ai-le-fonti-awards-2018

[52] AXA Is Using Ethereum's Blockchain for a New Flight Insurance Product. [Online] [Accessed 13.09.2017] Available: https://www.coindesk.com/axa-using-ethereums-blockchain-new-flight-insurance-product

[53] Assicurazione dei Rischi Calamità Naturali. Insuring Natural Catastrophe Risks. [Online] [Accessed 03.11.2000] 7th R.I.B. Convention, 2000. Available: http://www.ribgroup.com/pdf/RIB_Conv_2000.pdf

[54] Viriyasitavat W., Hoonsopon D. Blockchain characteristics and consensus in modern business processes. Journal of Industrial Information Integration 2019:13:32-39. doi:10.1016/j.jii.2018.07.004

[55] Forum W. E. Rischi dei cambiamenti climatici: il ruolo delle assicurazioni. (Risks of climate change: the role of insurance.) 2013. (in Italian)

[56] Campobasso G. Manuale di diritto commerciale. (Commercial law manual.) Torino: Utet Giuridica, 2015. (in Italian)

[57] Makhdoom I., et al. Blockchain's adoption in IoT: The challenges, and a way forward. Journal of Network and Computer Applications 2019:125:251-279. doi:10.1016/j.jnca.2018.10.019

[58] Andoni M., et al. Blockchain technology in the energy sector: A systematic review of challenges and opportunities. Renewable and Sustainable Energy Reviews 2019:100:143-174. doi:10.1016/j.rser.2018.10.014

[59] Min H. Blockchain technology for enhancing supply chain resilience. Business Horizons 2019:62(1):35-45. doi:10.1016/j.bushor.2018.08.012 
[60] Abirascid E. Banche, la sfida più grande è la blockchain. (Banks, the biggest challenge is the blockchain.) [Online]. [Accessed 11.06.2016]. Available: https://www.startupbusiness.it/banche-la-sfida-della-blockchain/86184 (in Italian)

[61] Sayegh K. Blockchain Application in Insurance and Reinsurance. France: Skema Business School, 2019.

[62] Banca d'Italia. Tassi di interesse. Analisi E Approfondimenti. (Bank of Italy. Interest rates. Analysis and deepenings) 2019. (in Italian)

[63] Jobst A. What is Securitization? Finance \& Development 2008:48-49.

[64] Breckner M., et al. Resilience to natural disasters - Insurance penetration, institutions, and disaster types. Economic Letters 2016:148:106-110. doi:10.1016/j.econlet.2016.09.023

[65] McAneney J., et al. Government-sponsored natural disaster insurance pools: A view from down-under. International Journal of Disaster Risk Reduction 2016:15:1-9. doi:10.1016/j.ijdrr.2015.11.004

[66] Leung M., et al. A comparative study of pricing approaches for longevity instruments. Insurance: Mathematics and Economics 2018:82:95-116. doi:10.1016/j.insmatheco.2018.06.010

[67] Wang L., et al. Cryptographic primitives in blockchains. Journal of Network and Computer Applications 2019:127:43-58. doi:10.1016/j.jnca.2018.11.003

[68] Oraee-Mirzamani B., Cockerill T., Makuch Z. Risk assessment and management associated with CCS. Energy Procedia 2013:37:4757-4764. doi:10.1016/j.egypro.2013.06.385

[69] Albatayneh A., Alterman D., Page A., Moghtaderi B. The Significance of Building Design for the Climate. Environmental and Climate Technologies 2018:22(1):165-178. doi:10.2478/rtuect-2018-0011

[70] Miezis M., Zvaigznitis K., Stancioff N., Soeftestad L. Climate change and buildings energy efficiency - The key role of residents. Environmental and Climate Technologies 2016:17(1):30-43. doi:10.1515/rtuect-2016-0004

[71] Bertoldi P., et al. Guidebook: How to develop a Sustainable Energy and Climate Action Plan (SECAP)? Publication Office of the European Union, 2018. doi:10.2760/68327

[72] Lamberti V., et al. Blockchain or not blockchain, that is the question of the insurance and other sectors. IT Professional 2017:99:1. doi:10.1109/MITP.2017.265110355

[73] Bølviken E., Guillen M. Risk aggregation in Solvency II through recursive log-normals. Insurance: Mathematics and Economics 2017:73:20-26. doi:10.1016/j.insmatheco.2016.12.006

[74] Bajcinovci B., Jerliu F. Achieving energy efficiency in accordance with bioclimatic architecture principles. Environmental and Climate Technologies 2016:18(1):54-63. doi:10.1515/rtuect-2016-0013

[75] Surminski S., Bouwer L. M., Linnerooth-Bayer J. How insurance can support climate resilience. Nature Climate Change 2016:6(4):333-334. doi:10.1038/nclimate2979 